Staphylococcus aureus surgical site infection. Infect Control Hosp Epidemiol 2008; 29:890-893.

10. Manian FA, Meyer PL, Setzer J, Senkel D. Surgical site infections associated with methicillin-resistant Staphylococcus aureus: do postoperative factors play a role? Clin Infect Dis 2003; 36:864-868.

11. Finkelstein R, Rabino $G$, Mashiah $T$, et al. Vancomycin versus cefazolin prophylaxis for cardiac surgery in the setting of a high prevalence of methicillin-resistant staphylococcal infections. I Thor Cardiovasc Surg 2002; 123:326-332.

12. Kallen AJ, Wilson CT, Larson RJ. Perioperative intranasal mupirocin for the prevention of surgical-site infections: systematic review of the literature and meta-analysis. Infect Control Hosp Epidemiol 2005; 26:916922.

13. van Rijen MML, Bonten $M$, Wenzel RP, Kluytmans JW. Intranasal mupirocin for reduction of Staphylococcus aureus infections in surgical patients with nasal carriage: a systematic review. J Antimicrob Chemother 2008; 61:254-261.

14. Ross H. Postoperative wound infection with methicillin-resistant staphylococci in general surgical patients. Aust $N Z$ J Surg 1984; 55:13-17.

\section{Pseudoinfection Due to Mislabeling}

To the Editor-Pseudoinfections and pseudooutbreaks are mainly caused by transfer of organisms between patient specimens (cross-contamination) and by contamination of patient specimens with environmental organisms. ${ }^{1,2}$ Other causes are clinical misdiagnosis and surveillance artifacts. ${ }^{2-4}$ The following example shows that further causes must be considered.

Salmonella enterica serovar Hadar was isolated on the same day from a stool specimen of patient $A$ and from an intestinal biopsy specimen of patient $B$. The patients were hospitalized in the same hospital but in different wards. An investigation was prompted, revealing that the patients had gone to the endoscopy suite concurrently on the day of specimen collection. An ileocoloscopy had been performed on patient A, including collection of mucosal biopsy specimens, whereas patient B had undergone gastroscopy without biopsy. No specimens at all had been collected from patient B that day to be sent to the microbiology laboratory. A stool specimen had been collected for microbiological examination from patient $A$, before patient $A$ went to the endoscopy suite that day. Patient B did not show clinical signs of salmonellosis, and a pseudoinfection was suspected. However, the pseudoinfection obviously could not have been caused by specimen contamination or cross-contamination. Observations of the work flow within the endoscopy suite led us to conclude that specimen mislabeling was the most likely cause of the pseudoinfection. The charts of the 2 patients had been deposited on the same desk. When the biopsy specimen was taken to the desk to be marked with a patient label, a label of patient $B$ was erroneously used for the biopsy specimen of patient $A$.

As in other cases published, this case of a pseudoinfection was noticed because of the unusual pathogen involved. Coincidentally, no biopsy specimen had been obtained from patient $B$ on the day of specimen collection. If this had not been the case, the pseudoinfection would not have been noticed at all, or cross-contamination would have been regarded as the most likely cause of pseudoinfection, leading to a costly analysis of endoscope processing as well as of each step in specimen collection and processing. ${ }^{1,3}$ Taking into account frequent errors in daily routine work, we hypothesize that pseudoinfection due to mislabeling of specimens is not an infrequent event.

\section{ACKNOWLEDGMENTS}

Potential conflicts of interest. Both authors report no conflicts of interest relevant to this article.

\section{Roland Schulze-Röbbecke, PD, MD; Claudia Schmitz}

From the Institute of Medical Microbiology and Hospital Hygiene, Heinrich-Heine-University of Düsseldorf, Düsseldorf, Germany (both authors).

Address reprint requests to Roland Schulze-Röbbecke, PD, MD, Institut für Medizinische Mikrobiologie und Krankenhaushygiene, Universitätsstr. 1, 40225 Düsseldorf, Germany (schulzrr@uni-duesseldorf.de).

Infect Control Hosp Epidemiol 2009; 30:408-408

(C) 2009 by The Society for Healthcare Epidemiology of America. All rights reserved. 0899-823X/2009/3004-0024\$15.00. DOI: $10.1086 / 59604 \mathrm{I}$

\section{REFERENCES}

1. Cunha BA. Pseudoinfections and pseudo-outbreaks. In: Mayhall GC, ed. Hospital Epidemiology and Infection Control. 3rd ed. Philadelphia: Lippincott Williams \& Wilkins; 2004:123-133.

2. Manangan LP, Jarvis WR. Healthcare-associated pseudo-outbreaks. Semin Infect Control 2001; 1:102-110.

3. Weinstein RA, Stamm WE. Pseudoepidemics in hospital. Lancet 1977; 2: 862-864.

4. Wendt $C$, Herwaldt LA. Epidemiics: identification and management. In: Wenzel RP, ed. Prevention and Control of Nosocomial Infections. 3rd ed. Baltimore: Williams \& Wilkins; 1997:175-213. 